JIME (Journal of Industrial and Manufacture Engineering)

\title{
Risiko dan Analisis Keputusan Solusi Material Obsolete Instrument dan Electrical Menggunakan Metode FMEA dan AHP
}

\section{Risk and Analysis of Material Solutions Obsolete Instrument and Electrical Using FMEA and AHP Methods}

\author{
Fachri Aan Silalahi*1) dan Willy Tambunan²) \\ Teknik Industri, Fakultas Teknik, Universitas Mulawarman, Indonesia \\ Diterima: Oktober; Disetujui: Maret 2020; Dipublikasi: Mei 2020; \\ * Corresponding author: fachri.98silalahi@gmail.com
}

\begin{abstract}
Abstrak
PT XYZ memiliki gudang sebagai tempat menyimpan dan merawat material sebelum digunakan dalam pabrik. Pada saat menyimpan material dalam gudang spare part ada material yang tidak dapat digunakan lagi atau disebut dengan obsolete. Material obsolete merupakan material yang sudah diganti dengan merk atau model atau tipe yang berbeda, telah rusak, telah lewat masa pakainya (expired) ataupun sudah tidak dapat digunakan lagi dipabrik serta material detection flag yang telah dilakukan proses duplikasi atau konsolidasi. Penumpukkan material obsolete terus bertambah dalam rak material penyimpanan merupakan risiko tertinggi dari identifikasi risiko menggunakan metode Failure Mode Effect Analysis (FMEA) dengan nilai severity 10, nilai occurance 9, dan nilai detection 6 dengan kategori risiko high $(\mathrm{H})$ yang memiliki nilai RPN sebesar 540. Berdasarkan data tersebut diperlukan solusi alternatif untuk mengatasi permasalahan tersebut mulai dari alternatif rent, donation, hingga pemusnahan material yang di proses melalui software expert choice V11 dengan metode Analythical Hierarchy Process (AHP).
\end{abstract}

Kata Kunci: Risiko, Alternatif, Obsolete, FMEA, Expert Choice, AHP.

\begin{abstract}
PT XYZ have warehouse as a place to safe material and treat material before it is used in factories. When saving material in a spare part warehouse there is a material that cannot be used anymore or is called an obsolete. Obsolete material is material that has been replaced with a brand or model or a different type, has been damaged, has expired (expired) or can no longer be used in the factory and the detection flag material that has been duplicated or consolidated. The accumulation of obsolete material continues to increase in the storage material rack is the highest risk of risk identification using the Failure Mode Effect Analysis (FMEA) method with severity value 10, occurance value 9, and detection value 6 with high risk category (H) which have an RPN value of 540 Based on the data, an alternative solution is needed to overcome these problems, starting from rent alternatives, donations, to the elimination of material that is processed through V11 expert choice software using the Analytical Hierarchy Process (AHP) method.
\end{abstract}

Keywords: Risk, Alternatives, Obsolete, FMEA, Expert Choice, AHP.

How to Cite: Silalahi, F.A. , Tambunan, W (2020), Risiko dan Analisis Keputusan Solusi Material Obsolete Instrument dan Electrical Menggunakan Metode FMEA dan AHP, JIME Journal of Industrial and Manufacture Engineering 4(1): 37 - 42 
Silalahi, F.A. , Tambunan, W, Risiko dan Analisis Keputusan Solusi Material Obsolete Instrument dan Electrical Menggunakan Metode FMEA dan AHP

\section{PENDAHULUAN}

Gudang PT XYZ mempunyai fungsi sebagai tempat untuk menerima dan merawat barang ataupun material yang digunakan sebagai penunjang segala aktivitas kegiatan perusahaan pabrik pupuk mulai dari material mechanical, instrument, dan electrical pada gudang spare part yang dimana material tersebut dikategorikan sebanyak 6 (enam) kategori yaitu kategori A atau fast moving, kategori $\mathrm{B}$ atau slow moving, kategori $\mathrm{C}$ atau non moving, kategori D atau insurance space, kategori E atau new item, dan kategori X atau obsolete.

Pergudangan tentunya memiliki risiko, salah satunya permasalahan terdapat pada barang kategori $\mathrm{X}$ atau obsolete yang merupakan material yang sudah diganti dengan merk atau model atau tipe yang berbeda, telah rusak, telah lewat masa pakainya (expired) ataupun sudah tidak dapat digunakan lagi dipabrik serta material detection flag yang telah dilakukan proses duplikasi atau konsolidasi. Material obsolete yang terdapat digudang menimbulkan berbagai persoalan seperti material tersebut masih memiliki nilai harga tetapi tidak dapat digunakan, penyimpanan barang obsolete memenuhi kapasitas ruang penyimpanan barang yang ada pada gudang spare part.

Penelitian ini bertujuan untuk mengetahui risiko tertinggi dari material obsolete instrument dan electrical serta memilih strategi mitigasi yang harus dilakukan oleh PT XYZ guna mengatasi risiko material obsolete tersebut.

Risiko adalah sesuatu yang mengarah pada ketidakpastian atas terjadinya suatu peristiwa selama selang waktu tertentu yang mana peristiwa tersebut menyebabkan suatu kerugian baik itu kerugian kecil yang tidak begitu berarti maupun kerugian besar yang berpengaruh terhadap kelangsungan hidup dari suatu perusahaan. Sehingga semua itu menuntut untuk melakukan antisipasi dari awal dalam menghadapi risiko agar risiko yang dihadapi tidak menimbulkan sebuah kerugian. Risiko yang ada merupakan sesuatu yang tidak dapat dihindari (Munawwaroh, 2017).

FMEA adalah sebuah metode evaluasi kemungkinan terjadinya sebuah kegagalan dari sebuah sistem, desain, proses atau servis untuk dibuat langkah penanganannya. Dalam FMEA, setiap kemungkinan kegagalan yang terjadi dikuantifikasi untuk dibuat prioritas penanganan. FMEA merupakan sebuah metodologi yang digunakan untuk mengevaluasi kegagalan terjadi dalam sebuah sistem, desain, proses, atau pelayanan (service). Identifikasi kegagalan potensial dilakukan dengan cara pemberian nilai atau skor masing-masing moda kegagalan berdasarkan atas tingkat kejadian (occurrence), tingkat keparahan (severity), dan tingkat deteksi (detection) (Puspitasari, 2014).

\section{METODE PENELITIAN}

Tahap pengolahan data dilakukan setelah diperoleh data-data dari hasil pengumpulan data. Pengolahan data yang dilakukan dengan cara identifikasi risikorisiko barang obsolete instrument dan electrical gudang spare part Departemen Penerimaan dan Pergudangan berdasarkan kategori risiko man, money, material, dan environment. Pengolahan data yang dilakukan dengan mengukur tingkat risiko berdasarkan skala severity, occurance, dan detection yang diukur oleh karyawan gudang spare part. Setelah dilakukannya pengukuran dari skala severity, occurance, dan detection maka 
dilakukan pemilihan tingkat risiko dengan menggunakan Risk Priority Number (RPN). Setelah itu mengumpulkan alternatif strategi yang telah dinilai dalam kuesioner oleh karyawan PT XYZ. Kemudian setelah didapatkan strategi penanggulangannya maka dilakukan pemilihan solusi yang terbaik dari setiap solusi yang didapatkan dengan menggunakan metode AHP (Analythic Hierarchy Process) pada pengolahannya di software expert choice V11.

Berikut ini merupakan rumus dari perhitungan Risk Priority Number (RPN): RPN = severity $\mathrm{x}$ occurrence $\mathrm{x}$ detection.

Tahap analisis merupakan tahap dimana data yang telah diolah kemudian dianalisis, pada penelitian ini analisis dilakukan identifikasi risiko yang dapat terjadi mulai dari risiko man, money, material, dan environment barang obsolete material instrument dan electrical kemudian memberikan cara penanggulangan terhadap barang obsolete tersebut.

Tahap penutup adalah tahapan terakhir yang dilakukan dalam penelitian pada tahapan ini berisikan kesimpulan dan saran. Kesimpulan yang dituliskan berdasarkan kepada tujuan yang telah dirumuskan sebelumnya. Saran yang diberikan berdasarkan pada perbaikan yang dapat dilakukan berdasarkan pada penelitian yang telah dilakukan.

\section{HASIL DAN PEMBAHASAN}

Hasil perhitungan kuesioner risiko FMEA barang obsolete instrument dan electrical dapat dijabarkan pada Tabel 1 sebagai berikut:
Tabel 1 Nilai RPN

\begin{tabular}{|c|c|c|c|c|c|c|}
\hline No. & $\begin{array}{l}\text { Kategori } \\
\text { Risiko }\end{array}$ & Risiko & Severity & Occurance & Detection & RPN \\
\hline \multirow[b]{2}{*}{1} & \multirow[b]{2}{*}{ Mon } & Penambahan beban kerja & 6 & 6 & 6 & 216 \\
\hline & & $\begin{array}{l}\text { Kejatuhan material pada saat } \\
\text { proses perawatan }\end{array}$ & 3 & 2 & 8 & 48 \\
\hline \multirow{3}{*}{2} & \multirow{3}{*}{ Money } & $\begin{array}{l}\text { Kerugian keuangan } \\
\text { pembelian barang tetapi } \\
\text { tidak digunakan }\end{array}$ & 9 & 8 & 5 & 360 \\
\hline & & $\begin{array}{l}\text { Kerugian keuangan dalam } \\
\text { preventive atau maintenance }\end{array}$ & 7 & 8 & 5 & 280 \\
\hline & & $\begin{array}{l}\text { Kerugian keuangan dalam } \\
\text { pemeliharaan listrik } \\
\text { (pencahavaan \& AC) }\end{array}$ & 6 & 8 & 4 & 192 \\
\hline \multirow[b]{2}{*}{3} & \multirow[b]{2}{*}{ Material } & $\begin{array}{l}\text { Korosi pada material } \\
\text { obsolete menvebabkan } \\
\text { kerusakan }\end{array}$ & 4 & 3 & 1 & 12 \\
\hline & & $\begin{array}{l}\text { Material obsolete mengalami } \\
\text { penurunan performa akibat } \\
\text { disimpan terlalu lama }\end{array}$ & 5 & 3 & 5 & 75 \\
\hline \multirow{4}{*}{4} & \multirow{4}{*}{ Environment } & $\begin{array}{l}\text { Penumpulkkan material } \\
\text { obsolete terus bertambah } \\
\text { dalam rak material }\end{array}$ & 10 & 9 & 6 & 540 \\
\hline & & $\begin{array}{l}\text { Suhu ruangan tidak sesuai } \\
\text { standard }\end{array}$ & 7 & 6 & 4 & 168 \\
\hline & & $\begin{array}{l}\text { Terhirupnya debu material } \\
\text { karena sirkulasi udara yang } \\
\text { kurang baik. }\end{array}$ & 9 & 6 & 3 & 162 \\
\hline & & $\begin{array}{l}\text { Ruang penyimpanan } \\
\text { material obsolete } \\
\text { menyebabkan kapasitas } \\
\text { gudang untuk material lain } \\
\text { berkurang }\end{array}$ & 8 & 9 & 2 & 144 \\
\hline
\end{tabular}

Berdasarkan hasil perhitungan RPN pada barang obsolete instrument dan electrical didapatkan RPN tertinggi pada penumpukkan material obsolete terus bertambah dalam rak material dengan RPN sebesar 540 yang terdiri dari nilai severity 10 , nilai occurance 9, dan detection 6. Maka dari itu, risiko ini akan dilakukan penanggulangan risiko dengan beberapa alternatif strategi penanggulangan risiko. Tujuan dari penanggulangan atau mitigasi risiko adalah sebagai berikut:

1. Menurunkan dampak risiko

2. Menurunkan frekuensi kegagalan

3. Meningkatkan kemampuan deteksi.

Setelah didapatkannya potential effect of failure, potential cause of failure, dan detection atau current control maka selanjutnya dilakukan penanggulangan atau mitigasi terhadap risiko tersebut. Penanggulangan risiko tersebut dapat dijabarkan sebagai berikut: 
Silalahi, F.A. , Tambunan, W, Risiko dan Analisis Keputusan Solusi Material Obsolete Instrument dan Electrical Menggunakan Metode FMEA dan AHP

\section{Intra Company Trade (J) \\ Perdagangan barang obsolete} instrument dan electrical yang dilakukan didalam sesama perusahaan.

\section{Discounted Sales (G)}

Penjualan barang obsolete instrument dan electrical dengan potongan harga.

\section{Direct Sales (I)}

Penjualan langsung barang obsolete instrument dan electrical (Benjaminsson dan Johansson, 2016).

\section{Auction (F)}

Lelang barang obsolete instrument dan electrical.

\section{Substitution $\mathbf{( H )}$}

Barang ditukarkan dengan material lain yang dibutuhkan oleh institusi.

\section{Recycle (E)}

Pemanfaatan kembali barang obsolete instrument dan electrical yang diubah menjadi barang lain yang memiliki fungsi dan kegunaan barang semula.

\section{Transfer (D)}

Secara fisik barang obsolete instrument dan electrical yang sudah tidak dibutuhkan dimutasikan ke unit kerja lain ataupun institusi cabang.

\section{Donation (B)}

Barang obsolete instrument dan electrical diberikan secara cuma-Cuma kepada pihak atau organisasi yang membutuhkan barang tersebut. Semisal dapat didonasikan ke institusi pendidikan guna menunjang proses pembelajaran disekolah.

\section{Elimination (C)}

Penghapusan logistic barang obsolete instrument dan electrical benar-benar dihilangkan atau dimusnahkan (Dwiantara dan Sumatro, 2004).

\section{Rent (A)}

Pengelolaan barang dapat dilakukan dengan cara disewakan dalam jangka waktu tertentu.

Sepuluh dari strategi penanganan risiko tersebut selanjutnya dilakukan pemilihan strategi yang tepat untuk menanggulangi risiko penumpukkan material obsolete terus bertambah dalam rak material menggunakan metode pemilihan strategi yaitu AHP dengan bantuan software Expert Choice dan kuesioner dari karyawan gudang spare part. Struktur hirarki menggunakan kriteria benefit, cost, opportunity, dan risk untuk membantu mempertimbangkan pengambilan alternatif strategi penanganan risiko yang tepat. Dalam penelitian ini untuk setiap alternatif strategi dijabarkan sesuai dengan kriteria benefit, cost, opportunity, dan risk. Seperti pada Gambar 1 sebagai berikut:

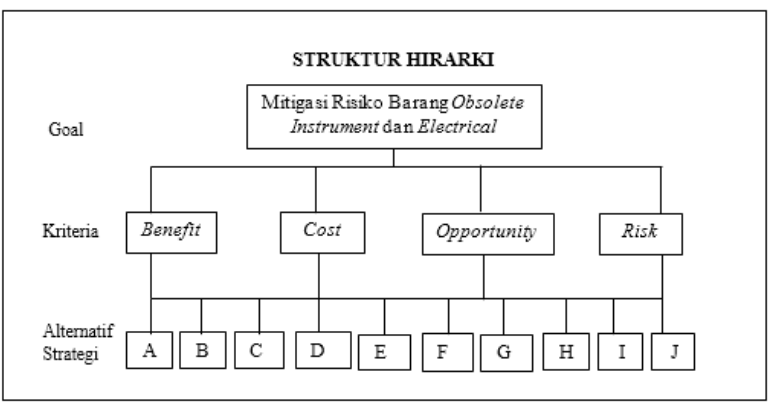

Gambar 1 Struktur Hirarki

Berikut ini merupakan nilai berdasarkan kuesioner dari kriteria BCOR yang ditunjukkan pada tabel dibawah ini: 
Tabel 2 Nilai Kriteria BCOR

\begin{tabular}{|c|c|c|c|c|}
\hline & Benefit & Cost & Opportunity & Risk \\
\hline Benefit & $\mathrm{X}$ & 8 & 5 & 6 \\
\hline Cost & $\mathrm{X}$ & $\mathrm{X}$ & $1 / 6$ & 7 \\
\hline Opportunity & $\mathrm{X}$ & $\mathrm{X}$ & $\mathrm{X}$ & 5 \\
\hline Risk & $\mathrm{X}$ & $\mathrm{X}$ & $\mathrm{X}$ & $\mathrm{X}$ \\
\hline
\end{tabular}

Berikut Hasil Perhitungan dari Nilai Kriteria BCOR ditunjukkan pada Tabel 3.

\begin{tabular}{|c|c|c|c|c|c|c|}
\hline & Benefit & Cost & Opprtunity & Risk & \multicolumn{2}{|c|}{ Eigenvector } \\
\hline Benefit & 4.471 & 17.623 & 76.200 & 59.000 & 157.294 & 0.553 \\
\hline Cost & 2.045 & 4.227 & 10.317 & 11.335 & 27.924 & 0.098 \\
\hline Opportunity & 2.469 & 9.190 & 51.200 & 28.800 & 91.659 & 0.322 \\
\hline Risk & 0.471 & 1.669 & 2.538 & 3.094 & 7.772 & 0.027 \\
\hline \multicolumn{3}{|c|}{ TOTAL } & & 284.648 & 1.000 \\
\hline
\end{tabular}

Tabel 3 Hasil Pembobotan BCOR

Kriteria benefit merupakan kriteria terpenting atau peringkat satu berdasarkan hasil dari kuesioner yang memiliki nilai 0,603 yang menjadikan kriteria ini sebagai kriteria yang dipilih dalam mitigasi risiko menggunakan software expert choice V11.

Hasil nilai pembobotan alternatif solusi software expert choice V11 seperti yang ditunjukkan pada Gambar berikut ini:

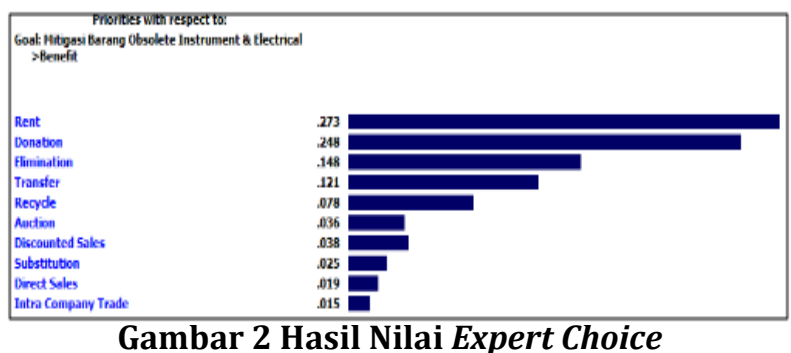

Gambar 2 Hasil Nilai Expert Choice

Berdasarkan hasil perhitungan maka didapati hasil pemilihan alternative solusi mitigasi risiko barang obsolete instrument dan electrical isiko barang obsolete instrument dan electrical yaitu dengan solusi rent karena memiliki nilai tertinggi yang dipilih menjadi prioritas utama untuk dilaksanakan yaitu pengelolaan barang dilakukan dengan cara disewakan dalam jangka waktu tertentu dengan nilai tertinggi berdasarkan pada software expert choice sebesar 0,273.

\section{SIMPULAN}

Hasil dari pengukuran risiko barang obsolete instrument dan electrical pada Departemen Penerimaan dan Pergudangan berdasarkan sisi man, money, material, dan environment didapatkan risiko dengan nilai RPN tertinggi yaitu penumpukkan material obsolete terus bertambah dalam rak material dengan RPN sebesar 540 yang terdiri dari nilai severity 10 , nilai occurance 9, dan nilai detection 6. Nilai RPN sebasar 540 termasuk dalam kategori high (H). Kemudian hasil dari cara penanggulangan didapatkan maka dipilih yang tepat berdasarkan penilaian dari karyawan pergudangan spare part dengan kriteria benefit, cost, opportunity, dan risk. Hasil dari perhitungan dengan menggunakan expert choice maka didapatkan cara penanggulangan yang tepat yaitu rent atau didefinisikan peminjaman barang obsolete instrument dan electrical dengan sewa dengan nilai 0,273 .

\section{DAFTAR PUSTAKA}

Aisyah. 2011. Implementasi Failure Mode Effect Analysis (FMEA) dan Fuzzy Logic Sebagai Program Pengendalian Kualitas. Journal of Industrial Engineering \& Management Sytems Vol. 2 No.2.

Andiyanto, dkk., 2016. Penerapan Metode Fmea (Failure Mode and Effect Analysis) Untuk Kuantifikasi Dan Pencegahan Resiko Akibat Terjadinya Lean Waste. Jurnal Online Poros Teknik Mesin Volume 6 No.1. Yogyakarta.

Hery. 2015. Manajemen Risiko Bisnis, Penerbit PT. Grasindo, Jakarta.

Munawwaroh. 2017. Analisis Manajemen Risiko pada Pelaksanaan Program Pendidikan dalam Upaya Meningkatkan Mutu Pendidikan. Jurnal Administrasi Vol. XXIV No.2 (Oktober 2017). Jakarta.

Pertiwi, H. 2017. Implementasi Manajemen Risiko Berdasarkan PMBOK untuk Mencegah Keterlambatan Proyek Area Jawa Timur 
Silalahi, F.A. , Tambunan, W, Risiko dan Analisis Keputusan Solusi Material Obsolete Instrument dan Electrical Menggunakan Metode FMEA dan AHP

(Studi Kasus PT. Telkom). Jurnal Studi Wati. 2012. Manajemen Risiko Bisnis. Jurnal Ekobis Menejemen dan Bisnis. Vol.4, N0 2 (2017). Surabaya.

Puspitasari, B., dan Martanto, A. 2014. Penggunaan FMEA dalam Mengidentifikasi Resiko Kegagalan Proses Produksi Sarung ATM (Alat Tenun Mesin) (Studi kasus PT. Asuputex Jaya Tegal. Vol. IX, No 2 (Mei 2014). Semarang. Ekonomi Bisnis dan Manajemen ISSN: 2088219X, Volume I, Nomor 4.

Yasa, dkk. 2013. Manajemen Risiko Operational dan Pemeliharaan Tempat Pembuangan Akhir (TPA) Regional Bangli di Kabupaten Bangli. Vol.1, No 2 (Juli 2013). Bali. 